\title{
EXCHANGE-TRADED FUNDS AND THEIR PERFORMANCE DURING THE COVID CRISIS
}

\author{
Nikola Stakići \\ Dharmendra Singh², \\ Luca Kuzevski Lunnemann ${ }^{3}$ \\ ${ }^{1}$ Singidunum University, \\ Belgrade, Serbia \\ ${ }^{2}$ Modern College of Business and \\ Science,Muscat, \\ Oman \\ ${ }^{3}$ CFA Level 1 Candidate, \\ Johannesburg, South Africa
}

\begin{abstract}
:
The subject of the paper is to analyze the industry of exchange-traded funds (ETFs), along with their basic characteristics. ETFs have been the most popular novelty in the financial industry in the previous three decades, demonstrating new investment vehicles; with variety of styles, sizes, risk spectrum and holdings' coverage. Analysis of the industry includes three most representative broad benchmarks and their associated tracking vehicles: SPY, VGK and IEMB; representing US, European and Asian markets, respectively. Analysis result implies superior risk-adjusted performance of Asian markets' ETF, given its emerging market status and more lucrative flexibility in flight of capital.
\end{abstract}

Keywords:

ETFs, financial markets, performance, COVID-19.

\section{INTRODUCTION}

Exchange-traded funds (ETFs) are hybrid investment vehicles that offer investors exposure to a plethora of asset classes and investment strategies. This hybrid characteristic refers to ETFs likeness to both open-end and closed-end mutual funds. Introduced just some 30 years ago, ETFs are now one of the fastest-growing segments of the investment management business. They provide liquid access to virtually every cor $\neg$ ner of the financial markets, allowing investors, both big and small, to build institutional-caliber portfolios with management fees significantly lower than those typical of mutual funds. High levels of transparency for both holdings and the investment strategy help investors easily evaluate an ETF's potential returns and risks (Hill, Nadig \& Hougan, 2015).

ETFs trade on an intraday basis and generally track an index, demonstrating characteristics of both mutual funds and stocks. While ETFs provide investors with exposure to a diversified investment opportunity, they are also low-cost, tax-efficient and transparent, which is why these investment vehicles are extremely popular. ETFs can also be divided into two strategy types: physical and synthetic. Physical ETFs hold the basket of securities under which it derives its value. Synthetic ETFs, on the other hand, track the value of an index through derivatives or swap agreements through a counterparty that promises to pay the value of the specified index to the fund. Therefore, whereas synthetic funds carry extra risk in the form of counterparty risk, they do have lower tracking errors than the traditional physical ETFs.

The History of Exchange traded funds dates back to the 1990s with one of the largest and most famous 'Spiders' (SPDR) ETF first sold in 1993. The reason for the emergence of this ETF was due to the demand for passive indexed investments for retail investors. ETFs initial performance was low and Assets under Management (AUM) of these funds were insignificant under the indexed funds category. However, from 1995 to 2001 their annual growth was around 132\% (Gastineau, 2002).
Correspondence:

Nikola Stakić

e-mail:

nstakic@singidunum.ac.rs 
This indicates the increased popularity as well as the importance of these investment vehicles. Since the introduction of ETFs in the 1990s, the number and variety of ETFs available to investors have grown at rapid pace. From only one ETF in 1993 to 102 by 2002 this number further increased to 1000 ETFs by 2009 and as of May 2020 there were more than $7100 \mathrm{ETFs}$ available to investors. This further emphasizes the popularity of the ETF market (Simpson, 2021).

Although ETFs have substantial benefits for the investor and the global economy, they do not come without risks for the investor and the global economy at large. While all ETFs are exposed to market risk, liquidity risk and price fluctuations, the more complex these vehicles get the higher the risks for investors are - counterparty risk, exotic-exposure risk, tax risks, to name a few (Foucher \& Gray, 2014). The performance of three ETFs, namely, SPY, VGK and IEMB will be analyzed as these ETFs represent the US, European, and Asian markets respectively and will serve as benchmarks for those markets. Additionally, the impact of the
COVID-19 pandemic on financial markets and the performance of ETFs during this period will be analyzed as well.

\section{ETF PERFORMANCE}

In the past decade, financial markets have witnessed a paradigm shift, when it comes to investing approach (Wigglesworth, 2018). Passive investing (and associated vehicles) has outperformed active funds, mainly due to ETFs existence and their constant evolving. For the past few decades passive funds had been catching up with active funds and as of September 2019 passive investments have triumphed over the active ones (Grittelsohn, 2019). Rising popularity can be shown with Figure 1 and Figure 2 , which display the growth trend of ETFs in assets under management as well as in the number of ETFs available to investors showing exponential growth that has accelerated in recent years.

Figure 1. Development of assets under management of ETFs worldwide (\$)

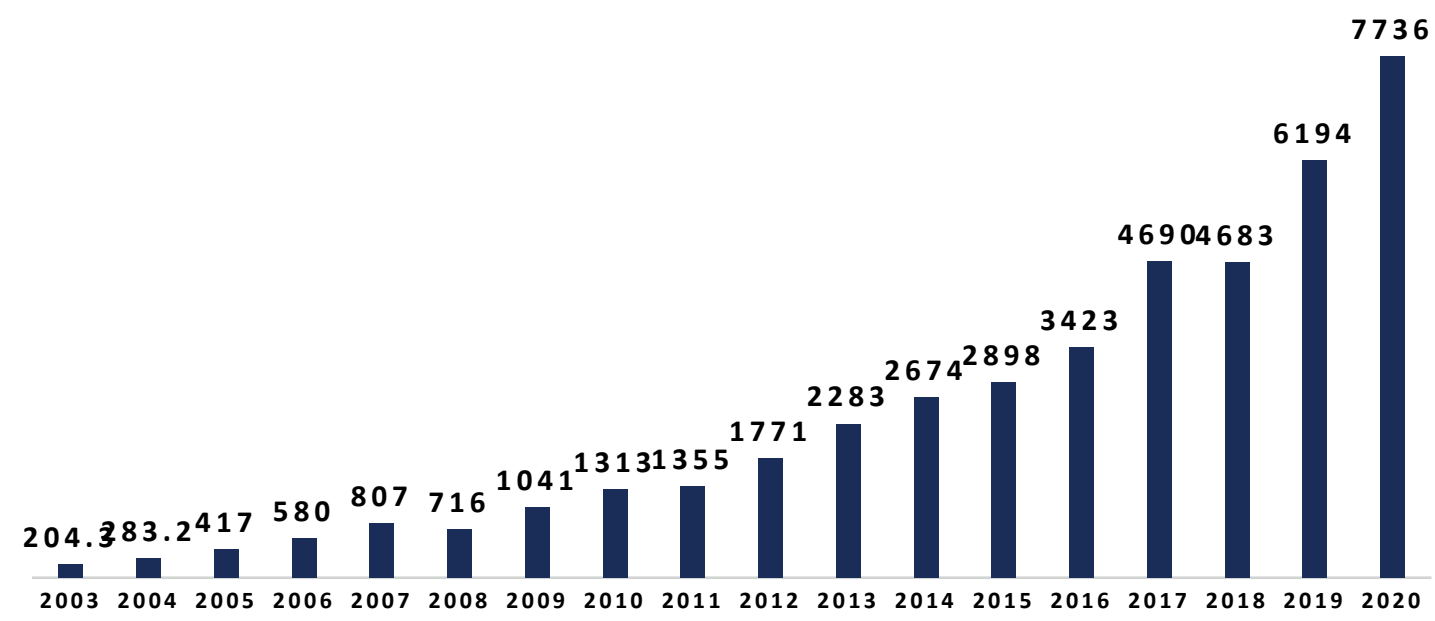

Source: Statista Research Department

Figure 2. Number of ETFs globally (period 2003-2020)

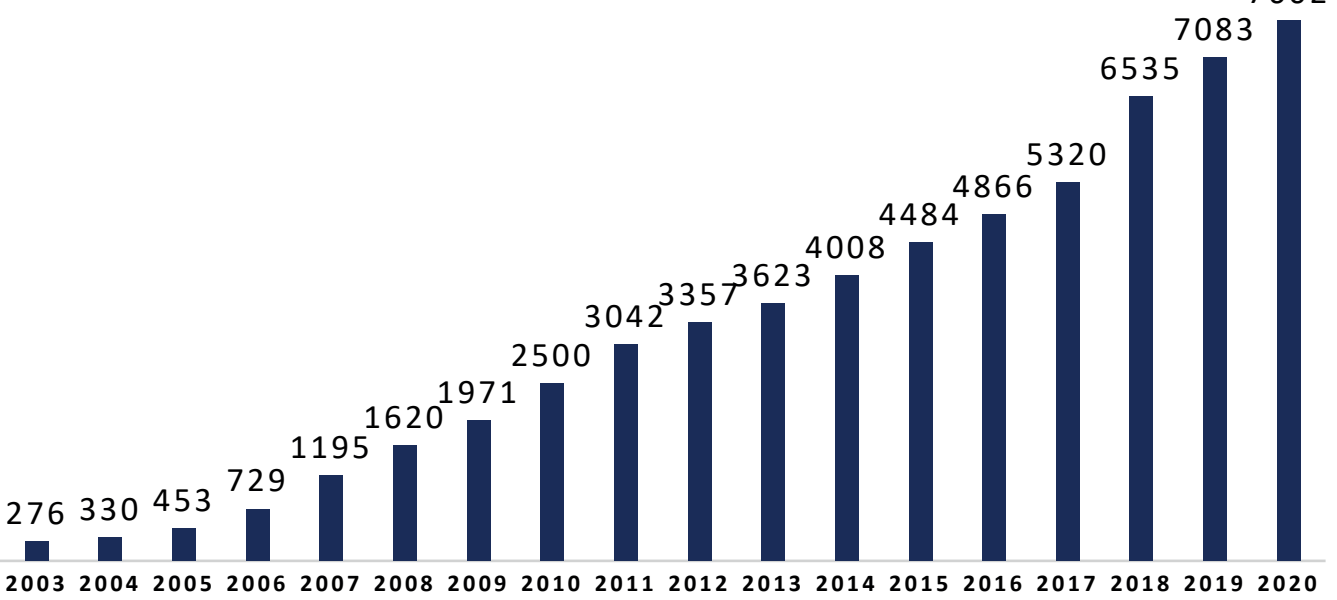


In order to show the performance of ETF industry, the analysis will be focused on three ETFs that cover three different markets, often considered as most representative ones:

1. SPY - ETF that tracks S\&P 500, the broad and most representative benchmark of US market

2. VGK - tracks Developed European markets based on FTSE Developed Europe All Cap Index and

3. IEMG - ETF that tracks MSCI' market-cap-weighted index of emerging-market firms in Asian countries.

SPY, more commonly known as SPDR or "Spiders" is the first and largest ETF on the market. SPY tracks the S\&P 500 and is the largest ETF by AUM as well as trading volume. This ETF is, therefore, representative of the US market. The VGK is an ETF that holds a broad, comprehensive portfolio of large, mid, and small-cap companies based in the developed regions of Europe including the UK. This ETF will be representative of the European market. Finally, the IEMG focuses on emerging markets and has a focus on Asian equities. The fund is designed to measure large, mid, and small-cap equity market performance. This will serve as representative of Asian market performance.

Following metrics will be used to analyze the performance of the three aforementioned ETFs: tracking error, alpha, R-squared, beta, standard deviation, as well as the Sharpe ratio. Additionally, the NAV return will be compared to the market return. It should be noted, however, that those metrics are just part of the larger universe of indicators, which are used to demonstrate various characteristics of the funds.

The tracking error of an ETF simply illustrates how closely the ETF tracks the index. The lower the tracking error the less the ETF will deviate from the performance of the index. The reported tracking error figure is typically only the annualized stan $\neg$ dard deviation of the daily differential returns of the ETF and its benchmark.

Alpha represents the portfolio's returns compared to the benchmark. If alpha is positive, this indicates that the portfolio or fund is outperforming the benchmark index. Conversely negative Alpha indicates that the portfolio or fund has underperformed relative to the benchmark index. Therefore, the closer alpha is to 0 the closer the fund replicates the returns of the benchmark index.

R-squared tells investors how much of the price movements that the fund experiences are related to or driven by the index from which it holds securities. This ratio or statistic is expressed as a value from 0-1 or more commonly as a percentage from $0 \%-100 \%$. If an ETF has R squared value of $100 \%$, this can be interpreted that all the movements in the prices of the ETF are perfectly correlated to movements in the benchmark index it tracks. Conversely, a $0 \% \mathrm{R}$ squared value shows zero correlation of price movements with the benchmark index.
Beta is a measure of systemic risk. It is essentially the covariance of a security or portfolio to the market index. The index by definition has a beta of 1 and as securities come close to one this means the portfolio or ETF moves with the market. Negative beta indicates an inverse relationship with the market movements, as the market goes up the portfolio will go down. Beta may however be greater than one. This would indicate greater volatility with the security or fund. Essentially gains and losses would be magnified. For example, a beta of 2 will increase in value twice as much as the market when the market is bullish and drop twice as low as the index in bear market movements.

Standard deviation is a commonly used measure of risk. It represents the dispersion of a dataset (returns) relative to the mean. The greater the standard deviation indicates a larger variance between historical returns and therefore higher risk. Conversely, lower standard deviation indicates less variance between historical return values and therefore indicates lower volatility and lower risk.

The Sharpe ratio is a relative measure of risk that captures the risk-adjusted returns of securities or portfolios. This ratio shows investors how attractive some returns are relative to their volatility or risk. The Sharpe ratio has become the most widely used measure of risk-adjusted returns. The NAV return represents the Net Asset Value returns of the ETF and their developments historically. The $\mathrm{NAV}$ is calculated by taking the total assets minus the total liabilities of the constituent holdings of the ETF and therefore will illustrate the performance of the fund when looked at historically. This is then compared to the market return to compare the performance of the ETF to the market as a whole. 
Table 1. ETF Fundamentals

\begin{tabular}{lccc}
\hline & SPY & VGK & IEMG \\
\hline Expense Ratio & $0.09 \%$ & $0.08 \%$ & $0.11 \%$ \\
\hline Tracking Error & $0.03 \%$ & $6.3 \%$ & $9.35 \%$ \\
\hline Net Assets & $\$ 361.9 \mathrm{~B}$ & $\$ 19 \mathrm{~B}$ & $\$ 82.0 \mathrm{~B}$ \\
\hline Median Bid/Ask Spread & $0.01 \%$ & $0.02 \%$ & $0.2 \%$ \\
\hline Volume & $56.5 \mathrm{M}$ & $2.1 \mathrm{M}$ & $2.2 \mathrm{M}$ \\
\hline Shares Outstanding & $\mathbf{8 5 6 . 6 \mathrm { M }}$ & $\mathbf{2 9 3 . 1 \mathrm { M }}$ & $\mathbf{1 . 2 \mathrm { B }}$ \\
\hline
\end{tabular}

Source: Fidelity.com

Table 2. ETF Fundamentals

\begin{tabular}{ccccccccc}
\hline SPY & NAV Return & $\begin{array}{c}\text { Market } \\
\text { Return }\end{array}$ & Alpha & R squared & Beta & $\begin{array}{c}\text { Standard } \\
\text { Deviation }\end{array}$ & $\begin{array}{c}\text { Sharpe } \\
\text { Ratio }\end{array}$ \\
\hline 1-Year & 40.15 & 40.25 & $-0.08 \%$ & $100 \%$ & $1.00 \%$ & $14.62 \%$ & 2.40 \\
\hline 3-Year & 17.87 & 17.86 & $-0.09 \%$ & $100 \%$ & $1.00 \%$ & $18.49 \%$ & 0.91 \\
\hline 5-Year & 17.03 & 17.07 & $-0.09 \%$ & $100 \%$ & $1.00 \%$ & $14.96 \%$ & 1.05 \\
\hline 10 -Year & 14.25 & 14.26 & $-0.09 \%$ & $100 \%$ & $1.00 \%$ & $13.58 \%$ & 1.01 \\
\hline
\end{tabular}

Source: Fidelity.com

Table 3. VGK Risk and return metrics

\begin{tabular}{ccccccccc}
\hline VGK & NAV Return & $\begin{array}{c}\text { Market } \\
\text { Return }\end{array}$ & Alpha & R squared & Beta & $\begin{array}{c}\text { Standard } \\
\text { Deviation }\end{array}$ & $\begin{array}{c}\text { Sharpe } \\
\text { Ratio }\end{array}$ \\
\hline 1-Year & 44.3 & 44.72 & $-8.90 \%$ & $93.86 \%$ & $1.29 \%$ & $19.11 \%$ & 2.03 \\
\hline 3-Year & 9.42 & 9.36 & $-0.06 \%$ & $95.61 \%$ & $1.11 \%$ & $20.01 \%$ & 0.48 \\
\hline 5-Year & 10.24 & 10.25 & $-1.39 \%$ & $93.63 \%$ & $1.11 \%$ & $16.81 \%$ & 0.60 \\
\hline 10 -Year & 6 & 5.94 & $-0.50 \%$ & $92.79 \%$ & $1.06 \%$ & $16.66 \%$ & 0.40 \\
\hline
\end{tabular}

Source: Fidelity.com

Table 4. IEMG risk and return metrics

\begin{tabular}{ccccccccc}
\hline IEMG & NAV Return & $\begin{array}{c}\text { Market } \\
\text { Return }\end{array}$ & Alpha & R squared & Beta & $\begin{array}{c}\text { Standard } \\
\text { Deviation }\end{array}$ & $\begin{array}{c}\text { Sharpe } \\
\text { Ratio }\end{array}$ \\
\hline 1-Year & 51.17 & 51.16 & $16.35 \%$ & $59.82 \%$ & $0.71 \%$ & $13.26 \%$ & 3.22 \\
\hline 3-Year & 9.11 & 9.15 & $0.36 \%$ & $86.57 \%$ & $1.01 \%$ & $19.22 \%$ & 0.48 \\
\hline 5-Year & 13.36 & 13.36 & $2.29 \%$ & $83.28 \%$ & $1.02 \%$ & $16.34 \%$ & 0.78 \\
\hline 10-Year & -- & -- & -- & -- & -- & -- & - \\
\hline
\end{tabular}

Source: Fidelity.com

SPY is the largest ETF on the market when looking at AUM (\$361.9B) and daily trading volume (56.5M). It is also one of the cheapest ETFs with an expense ratio of $0.09 \%$. One of the reasons for this cheapness, other than the fact that it employs a passive strategy, is the size of the fund, given that more assets flow into the fund and it becomes more efficient, and managers of the fund can afford to lower the expense ratio further.
With extremely high liquidity this also leads to a much lower bid/ask spread (0.1\%), as underlying assets of an ETF are more liquid, and the funds trading volume increases. Conversely, lower liquidity of underlying securities may lead to wider spreads for investors. 
SPY has experienced an Alpha of value very close to zero or just below it, which indicates that the fund does not outperform the market but rather underperforms relative to the market. However, the value is almost negligible and associated with minor explicit and implicit trading costs.

The value of R squared for SPY as well as the beta of 1 or $100 \%$ indicates that all the price movements of the fund can be derived from price movements on the market, and the beta indicates identical movement with the market. The historical returns of the SPY ETF have therefore mimicked the stock market almost identically and in the recent bull markets performed well, especially lately as markets have rebounded from the hits of the covid pandemic.

VGK or the European markets ETF, which also adopts a passive strategy of replication, has a low expense ratio of $0.08 \%$. The fund has about $\$ 19 \mathrm{~B}$ assets under management but unlike the SPY has a higher tracking error of 6.3 indicating more volatility relative to the SPY. This is due to a more active approach in that the fund holds companies that cross national borders, and this results in higher tracking errors. The fund is however liquid, and this can be seen in the low bid/ask spread of $0.02 \%$. The fund seems to be consistently underperforming relative to the market especially in recent years with the 1-year alpha value of $-8.9 \%$ value. However, the 3 -year, 5 -year and 10 -year alpha values are near 0 at $-0.06 \%,-1.39 \%$ and $0.5 \%$ respectively. The $\mathrm{R}$ squared values for VGK indicate a high portion $90 \%+$ of the returns that are driven by the market movements. The 1-year beta of 1.29 further reinforces the previous indication of more volatility seen in the tracking error. However, the 3-year, 5-year, and 10year beta are similarly above 1 but lower than the previous year (1.1; 1.1 and 1.06 respectively).
IEMG, or the emerging Asian market ETF is the youngest among the funds in the analysis and is the second-largest out of the three, with AUM of $\$ 82.0 \mathrm{~B}$. The expense ratio is $0.11 \%$. The tracking error is the highest out of the three ETFs at 9.35, also having a comparatively larger median bid/ask spread at $0.2 \%$. The IEMG market in the previous year has performed well above that of the index it tracks as indicated in the alpha (1- year) of $16.35 \%$. This occurrence however was lacking when compared to the alpha over the longer periods of time with the 3 -year alpha of $0.36 \%$ and the 5 -year alpha value of $2.29 \%$. The $\mathrm{R}$ squared values in the 5-year and 3-year time frame are in the $80+\%$ indicating a moderate to high level of price movement driven by the index. However, the 1-year $\mathrm{R}$ squared ratio of only $59.82 \%$ further explains the improved performance relative to the market as shown in the 1 -year alpha (16.35\%). The 1-year beta of 0.71 indicated the ETF moves with the market at a lower degree and the beta over the longer periods has been near the market beta of 1. (3-year and 5-year of 1.01 and 1.02, respectively).

In the shorter term, the 1- year period, IEMG has the better risk-adjusted returns as indicated in its Sharpe ratio of 3.22; 119 basis points higher than VGK and 82 basis points higher than SPY. However, over the longer term, SPY has the better risk-adjusted return with a Sharpe ratio of 1.05 (5-year as the time frame is available with all ETFs) compared to 0.60 for VGK and 0.78 for IEMG.

Figure 3. Sharpe ratio of three representative ETFs

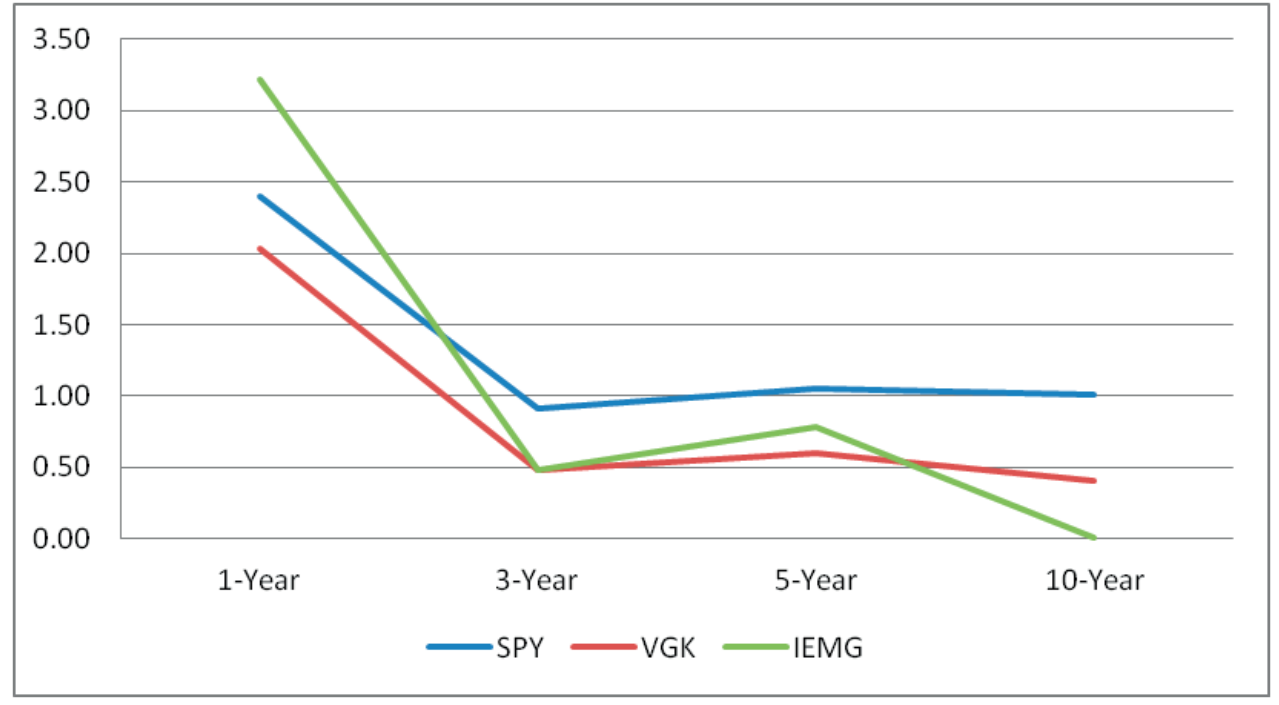


Figure 3 shows that Asians markets ETF has outperformed the other markets from a risk standpoint, given that it had a lower level of risk and higher Sharpe, especially for a shorter, i.e., 1-year time frame. This can be seen in the 1-year alpha of 16.35 as well, however, these returns were not characteristic of the overall market as the R squared value for IEMG of 59.82 indicates lower performance attribution to the tracking index.

\section{THE IMPACT OF COVID-19 ON ETF INDUSTRY}

The outbreak of the COVID-19 virus forced authorities and governments to take unprecedented measures that effectively shut down the business for some period of time. These measures led to a drastic reduction in economic activity. As cross border travel and public life were cut down to a minimum the impact on economies was severe.

ETFs during the crisis were however more resilient than alternative investment options. ETFs in a crisis are affected when looking at the premiums/discounts to NAV seen as the markets scramble. Discounts refer to the scenario when the security (bonds) trade at a price that is below the intrinsic/face value of the security which occurs for several reasons, including increasing interest rates or turmoil. Conversely, premiums refer to the price of the security being sold at above the price of the security for similar reasons. This characteristic was seen in several asset classes including US treasury ETFs. During the Covid pandemic discounts/premium in the fixed income category experienced these premium/discounts to a larger extent. This is a common result with fixed income (bonds) securities since they are usually less liquid than other investment classes. During March 2020, the investment grade corporate Bond ETFs were trading at an average discount of $3.36 \%$ to NAV and in some severe cases 7\% (The Investment Association, 2020). At times of high volatility, which includes the first weeks of the impact of the pandemic on financial markets in March 2020, markets amplify these small differences between tradable and indicative bond prices to a much larger extent which resulted in these large gaps in the premiums and discounts to NAV. This would usually incentivize the participants in ETF's mechanism to intervene and start the arbitrage mechanism. However, no significant arbitrage occurred, resulting in the ETFs remaining at prices below the NAV for a few weeks, demonstrating heightened levels of illiquidity.

The next point of interest is to examine the liquidity and trading volume of ETFs. Historically the trading volumes of ETFs have risen in times of market stress (Kolakowski, 2019). This happens because ETFs provide markets with liquidity when underlying market trading is impaired. The early weeks of the pandemic were no exception and resulted in an enormous amount of trading that brought trading levels of ETFs to extreme highs. The ETF liquidity was much higher than that of the underlying securities. On March 12th, BlackRock's USD Corporate Bond ETF changed hands 1000 times while the underlying's only 37 times. On the most volatile trading day in 2020, secondary trading volumes of ETFs made up 34\% of all cash equity trading in the European markets and a staggering $41 \%$ in the US when compared to 2019 when it was $21 \%$ and $27 \%$, respectively (Blackrock and Bloomberg, 2020). These statistics illustrate how investors turn to ETFs when markets are stressed.

The bid/ask spread of ETFs increased just like the rest of the market. This is common in times of crisis when market makers attempt to price in risk to securities (increase the price to reflect the newfound risks in the market). All securities that trade on the secondary markets display two prices the bid price and the ask price. The bid price is the price at which the market is willing to purchase securities or ETFs from investors while the ask price is the price at which investors will buy these same securities from the market. Naturally, the bid price is lower than the ask price and the difference represents the profit that the financial institutions make from trading and is therefore known as the bid/ask spread. The narrower the spread the more liquid the shares and vice versa. Supply and demand factors impact the spread by widening the spread meaning that the difference between the two prices increases. This generally occurs in worsening economic conditions as dealers require higher compensation for the added risk on the market, and conversely, the narrowing of a spread means the two prices move closer together and are indicative of improving economic conditions. Generally, in normal market conditions, the bid/ask spread on ETFs is narrower than the spread on the underlying securities the reason being as ETFs AUM increases the volume of trading also increases naturally as multiple dealers trade the ETFs further tightening the spread (Boyde, 2021). This adds to the benefits of ETFs and their efficient nature as well as their low-cost characteristic relative to the underlying securities in the portfolio.

During the crisis, as mentioned before, the bid/ask spreads on the market widen, however, the ETF spreads tend to widen less than their underlying securities in the portfolio. This depends on the willingness of the dealers to maintain and provide two-sided quotes. During the COVID pandemic, in March specifically, the spreads on ETFs widened albeit less than the securities. The large cap equities (most liquid part of the secondary market) widened as well. As seen in figure 12, the spread on the top 5 largest ETFs tacking the S\&P 500 fluctuated less than the securities in their portfolios. 


\section{CONCLUSION}

ETFs have changed the face of investing with several benefits, proving to drive the increasing popularity of ETFs. Those benefits include, among others, low cost, transparency, tax efficiency access and liquidity. Passive investing has been proven, on average, to outperform the more actively managed funds in the past.

ETF performance of SPY, VGK and IEMG illustrated the performance of the US, European and Asian markets respectfully. Over the longer term, the SPY has performed more consistently. Recently, over the past year, the Asian market ETF experienced the best performance out of the 3 ETFs with 51.17-point increase versus the 44.3 in the VGK and 40.15 in the SPY. On a risk-adjusted bases the IEMG had strong performance in the past year with the highest Sharpe ratio of 3.22 versus the 2.03 for VGK and 2.40 for SPY possible due to the Asian market rebound to the pandemic and performance in recent years in technology and semiconductor industries. The investment world and ETF, in general, are shifting to a more Macroeconomic view of the world and the increasing popularity in factor-based investing and Thematic investing has increased and is predicted to further increase in the near future as younger investors attempt to predict and shape the future developments that could lead to a better future for us all.

The COVID-19 pandemic struck the world by surprise and had severe impacts on the global economy as a whole. As countries closed their borders and implemented lockdowns, the economy was effectively shut down in the few weeks or a month in 2020 around Feb/March. ETFs however were resilient during these troubled times relative to other asset cases and investment options. The trading volumes increased significantly, and concerns were raised about the effects these instruments would have on the economy as it was expected that APs would step away from their duties as ETF price stabilizers and liquidity providers. However, this did not occur, and primary and secondary trading volumes increased. The bid/ask spreads of ETFs did increase with the markets as expected in a time of crisis but to a lower degree than the underlying securities. Although there has been some backlash to the ETF space as some people believe the price discovery mechanism is corrupt, and that they pose a systematic risk to finance as they persuade investors into the deeper, more complex parts of the market with specific ETF offerings. What is clear is that as these investment vehicles grow, and expand further, and become more complex, so does most of our knowledge of them. ETFs need to be used appropriately and thorough education and understanding of them are paramount.

\section{LITERATURE}

Boyde, E. (2021). Concerns grow over ETF's illiquid holdings. Financial Times. https://www.ft.com/content/fa3aa0bfed90-40e6-ac56-ca97d21856d3.

Foucher, I., \& Gray, K. (2014). Exchange-traded funds: Evolution of benefits, vulnerabilities and risks. Bank of Canada Financial System Review, 42-43.

Gastineau G. L. (2002). The Exchange-Traded Funds Manual, John Wiley \& Sons, New York.

Grittelsohn,J. (2019, September 11). End of an era: Passive Equity Funds Surpass Active in Epic Shift. Bloomberg https://www.bloomberg.com/news/articles/2019-09-11/ passive-u-s-equity-funds-eclipse-active-in-epic-industry-shift

Hill, J. M., Nadig, D., \& Hougan, M. (2015). A comprehensive guide to exchange-traded funds (ETFs). CFA Institute Research Foundation.

Kolakowski, M. (2019, August 16). Why passive ETF's face big risks in a liquidity crisis. Investopedia. https://www. investopedia.com/why-passive-etfs-face-big-risks-inliquidity-crisis-4767714

Simpson, S. D. (2021, Feb 5). A Brief History of ExchangeTraded Funds. Investopedea. https://www.investopedia. com/articles/exchangetradedfunds/12/brief-history-exchange-traded-funds.asp 